\title{
China's way from \\ conventional power grids towards smart grids
}

3.1 Historical perspective - 20

3.2 Today's power system and its most pressing challenges - 22

3.2.1 Power generation - 22

3.2.2 Power consumption - 25

3.2.3 Power logistics - 26

3.3 Smart grid development in China - 27

3.3.1 Motivation for smart grids in China - 27

3.3.2 China's technological view of the smart grid - 28

3.3.3 This study's view on smart grids in China - 30

3.4 The regulation of China's electric power system - 31

3.4.1 Policy setting and fundamental institutions - 31

3.4.2 Market structure - 34

3.4.3 Market design and RES integration - 35

3.4.4 Development of infrastructure and network regulation - 37

3.4.5 Coordination of generation and consumption - 38

3.4.6 The role of information and communication - 40

References - 42 


\section{Chapter at a glance}

- The chapter gives an overview of the existing electric power system, the envisaged development of smart grids, and the regulatory environment in China. The main aspects emphasized in this chapter serve as a guideline for the description of the German background in Chap. 4 and the recommendations and regulatory pathways in - Chaps. 5 and 6.

- $\quad$ Section 3.1 gives an overview of the more recent development of the power sector to lay a solid foundation for identifying the challenges currently facing the sector.

- Section 3.2 presents an overview of the physical structure of China's current electric power system and discusses in detail the main technological challenges in this context.

- Section 3.3 introduces the Chinese smart grid vision resulting from the specific technological challenges. In this respect, the role of the government and the ICT industry in developing the Chinese smart grid vision is especially emphasized.

- Section 3.4 describes the regulatory framework of the electric power system in China on the basis of the regulatory areas defined in $>$ Sect. 2.3. A clear focus is thereby on regulatory circumstances representing a barrier to smart grid development in China.

\subsection{Historical perspective}

Towards a reform of the power sector In the past 15 years, a series of reforms have greatly improved the efficiency, reliability, and environmental performance of the Chinese power sector. However, significant challenges remain: rapidly rising electricity demand, concerns about power system reliability and energy security, environmental degradation and climate change [1].

Historically, all stages of China's power sector value chain - from generation, transmission and distribution to retail - were owned and operated directly by the central government. By the mid- $1980 \mathrm{~s}$, in the wake of China's opening up policy, a first set of reforms allowed new market actors, mostly provincial and local governments, to invest in power generation. This created a boom of so-called inde- pendent power producers (IPP), thereby alleviating power shortages. Today, IPP make up more than half of China's power generation assets.

In 1997, the former Ministry of Electric Power (MoEP) was dissolved and the generation, transmission and distribution assets previously under direct government control were transferred to the newly formed State Electric Power Corporation (SEPC). This marked a significant step towards the separation of market functions fulfilled by state-owned enterprises (SOE) and government regulatory authority.

In 2002, the State Council of the People's Republic of China promulgated a landmark reform for restructuring the Chinese power sector by separating power generation from grid operation (transmission $\&$ distribution). In the course of the reorganization, the vertically integrated SEPC was dismantled and its assets divided into eleven new SOE: two grid operators, five power generation companies, also known as Big Five (China Huaneng Group, China Datang Corporation, China Huadian Group, China Guodian Corporation, China Power Investment Corporation), and four power service companies providing advisory and ancillary services. At the same time, the State Council established a ministerial regulatory authority, the State Electricity Regulatory Commission (SERC), to oversee the developing competitive market structure and further push power sector liberalization and market-based reform. The aim of this major power sector reform was to:

- break-up the power sector monopoly and introduce fair competition (mainly on the generation side) within the framework set by the regulator,

- improve economic efficiency and reduce costs,

- rationalize the electricity tariff system and optimize resource allocation,

- promote the development of the power industry and push ahead nationwide interconnection,

- set up an open, orderly and well- developed power market based upon the principles of separation of governmental oversight and power sector enterprises.

In retrospect, the reforms are considered a significant step towards the diversification of Chi- 
na's power sector market structure. However, the market-oriented reform of the power sector - as it had originally been envisaged by the State Council - stalled after these initial steps. No progress was made in unbundling the grid operators' transmission and distribution assets or in introducing more market-based electricity prices. This lack of progress despite ambitious plans for further reforms may be attributed in part to a lack of power and independent decision-making authority of the newly established regulator SERC, which suffered from very limited jurisdiction, capacity and resources. The National Development and Reform Commission (NDRC) is a successor to the State Planning Commission (SPC), which was renamed to State Development Planning Commission (SDPC) in 1998. In March 2003 the SDPC merged with the State Council Office for Restructuring the Economic System and parts of the State Economic and Trade Commission to form NDRC, which remained the most powerful policymaker for the power sector, retaining competence over electricity pricing and major energy project approval. The emergence of the newly formed State Grid Corporation of China (SGCC, in charge of $80 \%$ of China's electricity grid) as a powerful influence in national energy policies further hampered the stride towards liberalization of the sector. In the most recent government restructuring in March 2013, the SERC was integrated into the National Energy Administration (NEA), an institution responsible for energy planning under the NDRC.

The trend towards low carbon development For a long time, progress in the electrification process together with the provision of a reliable and affordable power supply were the main priorities of China's government in its efforts to promote industrial and economic development. In the last two decades, questions relating to the sustainability of the electric power system have steadily gained increasing importance in China.

Energy efficiency and environmental protection were first put forward as a prominent policy objective for power sector development in China's general energy law - the 1995 Electric Power Law [2]. On the one hand, the law aimed at legalizing the status of power generation companies as com- mercial entities and at establishing the legal basis for private ownership [3]. On the other hand, the law stressed the importance of the environmental sustainability of the development of the power system by stipulating that

I) the construction, production, supply and utilization of electric power shall protect the environment according to law, adopt new technologies, minimize discharge of poisonous waste, and prevent pollution and other public hazards. The state encourages and supports electricity generation by using renewable and clean energy resources. [4]

The shift towards environmental protection was reiterated in the 1998 Energy Conservation Law and the 2006 Renewable Energy Law, which respectively aim at promoting energy efficiency and deploying RES. The Renewable Energy Law has laid a solid legal foundation that has since been followed by a number of key implementation guidelines detailing national renewable energy targets, a mandatory connection and purchase policy, a national feed-in tariff system for wind and solar energy as well as arrangements for cost-sharing and funding of renewable energy incentives.

China put forward aggressive measures to reduce the energy intensity of its economy: in its $11^{\text {th }}$ (2006-2010) Five-Year plan, China set a target of reducing its energy intensity, measured as energy consumption per unit of gross domestic product (GDP), by $20 \%$. At the world climate conference in Copenhagen in 2009, China complemented this target with an overarching goal to reduce carbon intensity, the measure of carbon dioxide emissions per unit of GDP, by $40 \%$ to $45 \%$ by 2020 compared to 2005 levels. The targets are backed up by comprehensive plans featuring numerous measures to facilitate increased energy efficiency and reduced emissions across different sectors. One of these efforts is the Small Plant Closure Program established in the $11^{\text {th }}$ Five-Year Plan. It focused on closing down small and inefficient power plants and replacing them with larger state-of-the-art facilities. In the period from 2006 to 2010, more than $70 \mathrm{GW}$ of coal-fired power generation capacity was shut down in the context of this program [5]. The program not only targeted power plants, but also facilitated the shut- 


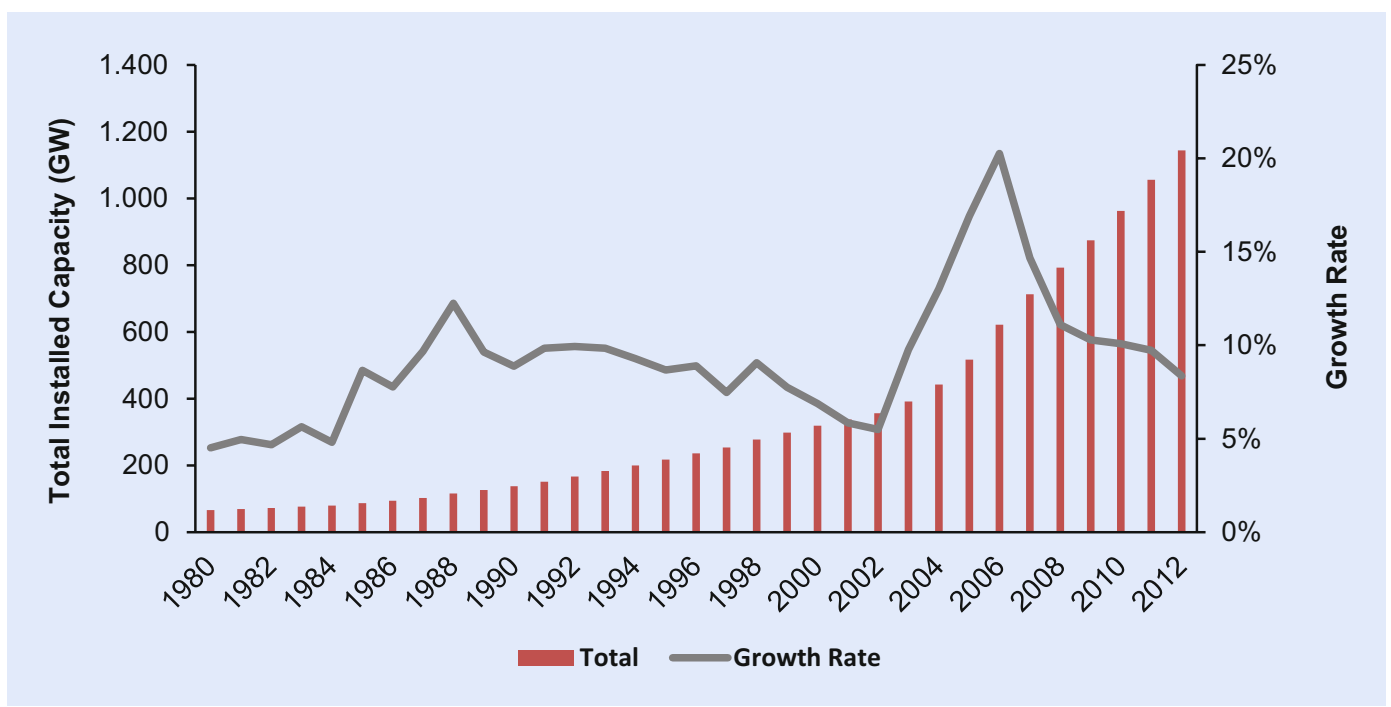

- Fig. 3.1 China's power generation capacities from 1980 to 2012, data from [10]

down and replacement of a large number of outdated small factories of energy-intensive industries, e.g. in the iron and steel and cement sectors. More recently, small coal mines and inefficient pulp and paper mills have been subject to this government policy promoting consolidation and modernization of its heavy industry.

The Top 1000 Enterprises Energy Saving Program was another measure of the $11^{\text {th }}$ Five-Year Plan to improve industrial energy efficiency by targeting China's largest energy consuming companies, which accounted for almost half of total industrial energy consumption and one third of total primary energy consumption in China. The program reportedly realized total energy savings of 150 million tons of coal equivalent, $50 \%$ more than originally planned [6]. The ambitious targets and extensive efforts to promote energy efficiency and adjust China's energy mix through the deployment of renewable energies are evidence of China's commitment to decouple its economic growth from the growth of energy demand and emissions - to reduce the carbon intensity of its economy and fight pollution.

An increasing factor influencing China's energy and industrial policy is the increasing public awareness of environmental pollution and its detrimental effects on the ecosystem and on people's health. In particular, the extreme levels of air pollution in major Chinese cities may be seen as a potential source of social unrest and has thus been given great attention by the Chinese government, especially after the serious pollution events in Beijing in January 2013 saw particulate matter air pollution levels rise to figures exceeding the 24-hour mean level recommended by the World Health Organization (WHO) by more than 30 times.

\subsection{Today's power system and its most pressing challenges}

\subsubsection{Power generation}

Compared to international averages, China's per capita reserves of coal, petroleum, and natural gas are rather low, a situation which in recent years has resulted in an increasing dependence on the import of fossil fuels [7]. In contrast, China is endowed with large renewable energy resources - estimated at $250 \mathrm{GW}$ and $750 \mathrm{GW}$ for onshore and offshore wind respectively, plus significant solar energy resources [8]. Since the 1980 s, China's power generation capacity has been steadily expanding (see - Fig. 3.1). From 2006 to 2012, total installed capacity almost doubled, increasing from $621 \mathrm{GW}$ to $1,147 \mathrm{GW}$ [9].

Coal is currently the primary source of electricity generation in China; in 2012 it accounted 


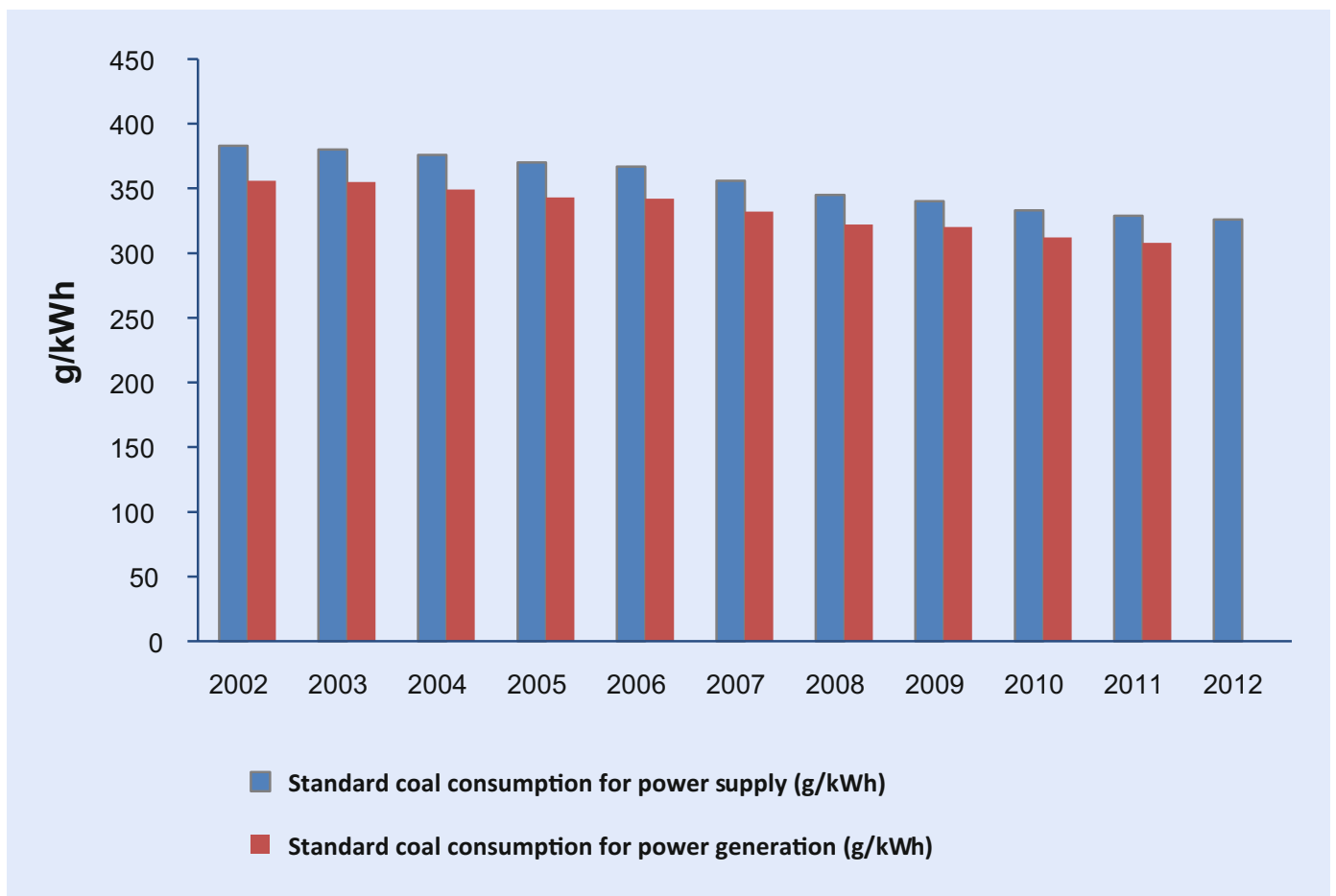

- Fig. 3.2 Standard coal consumption (2002-2012), data from [10]

for close to $80 \%$ of total electricity generation [9]. This massive reliance on coal for power generation and industry makes China the biggest $\mathrm{CO}_{2}$ emitter worldwide [11]. The second pillar of China's electricity generation mix is hydro power, which has a share of roughly $17 \%$ of total electricity generation. Nuclear and wind power contribute a share of roughly $2 \%$ each. Other sources, such as gas, solar, and biomass power, with shares of less than $1 \%$ each, currently play no more than a minor part in China's power mix [9].

Although China's generation mix has been relatively stable over the past two decades, the composition of the country's coal-fired power plants has undergone a significant shift toward larger and more efficient units, especially during the $11^{\text {th }}$ Five-Year Plan. By implementing the policy of replacing smallsize units by large and efficient plants, the share of units with $300 \mathrm{MW}$ and above rose from $42.67 \%$ of total thermal generating capacity in 2000 to $89.1 \%$ by the end of 2010 . As a result, the standard coal consumption per $\mathrm{kWh}$ generated has been reduced significantly (see - Fig. 3.2).
With the introduction of the Renewable Energy Law in 2006, China triggered a boom in the expansion of renewable energy development (• Fig. 3.3). China has since become the world's largest producer of wind power, with approximately $13 \mathrm{GW}$ installed in 2012 reaching a total installed and gridconnected capacity of $61.4 \mathrm{GW}$. With the introduction of financially attractive feed-in-tariffs in 2013, China has also recently become the world's biggest market for solar PV with record installations of around $14 \mathrm{GW}$, more than $11 \mathrm{GW}$ of which is gridconnected [9].

China's electricity system, however, is not wellprepared for such a rapid increase of intermittent wind and solar generation units. Due to the lack of gas-fired power plants in China, coal-fired power plants are mainly employed for load-following and peak generation. These activities require a significant cycling reducing the operational efficiency of coal-fired power plants [12]. Also, limited interregional transmission capacities often complicate the usage of hydro power plants for load-following and peak generation. This contributes to high grid 


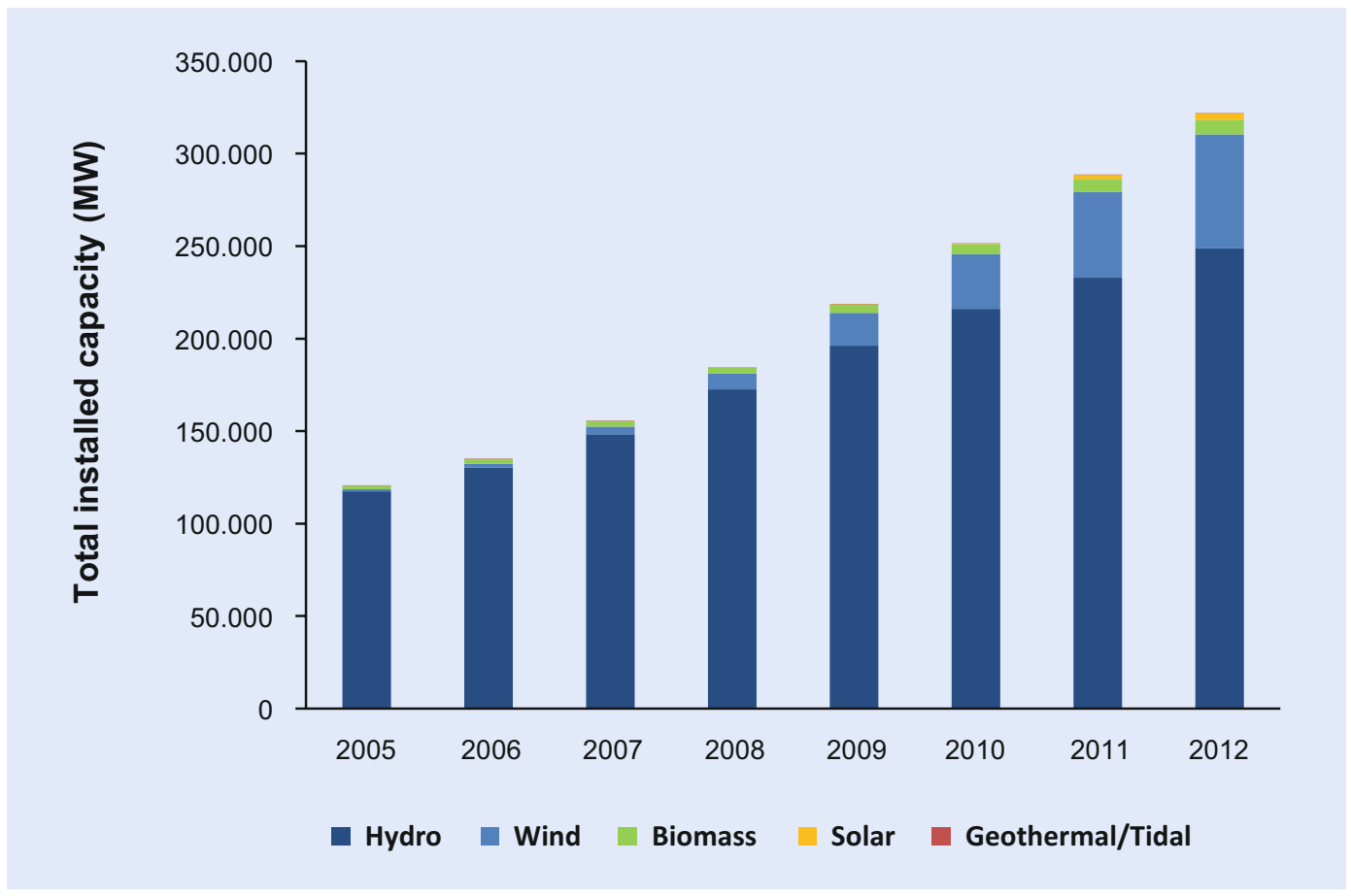

Fig. 3.3 Installed capacities of renewable energies (2005-2012), data from [10]

integration costs for wind and PV power in China [12].

Another challenge of the rapid build-up of renewables is that grid connection is lagging behind. Wind turbines are erected much faster than power lines are built. Realizing this problem, the government has made efforts to slow wind power expansion in order to reduce the share of wind power capacity which is installed but not grid-connected (by year-end) from 30 to $20 \%$ in 2012. Due to the heavy concentration of wind power in remote regions with rich wind resources and in so-called wind power bases with $10 \mathrm{GW}$ and more capacity, curtailment due to grid congestion has become an important issue: 20 TWh of wind power had to be curtailed in 2012 [13], representing about $20 \%$ of total electricity generation from wind [14]. Since financial losses due to curtailment are not reimbursed to RES owners, wind power developers exposed to the negative impact of curtailment are increasingly building wind farms in lower wind speed regions with less network congestions.

\section{Challenges in China's power generation} sector

- China is not particularly well endowed with fossil energy resources in per capita terms. A system relying on fossil-fueled generators may create an increasing dependence on foreign energy sources.

- China's heavy reliance on coal for power generation and industrial processes is contributing to high air pollution levels and $\mathrm{CO}_{2}$ emissions.

- Employing coal-fired power plants for loadfollowing and peak generation reduces the efficiency of their operation.

- Renewable energy deployment is poorly coordinated with grid development, so that grid connection is lagging behind the construction of renewable power plants and significant quantities of wind power are being curtailed due to grid congestion. 


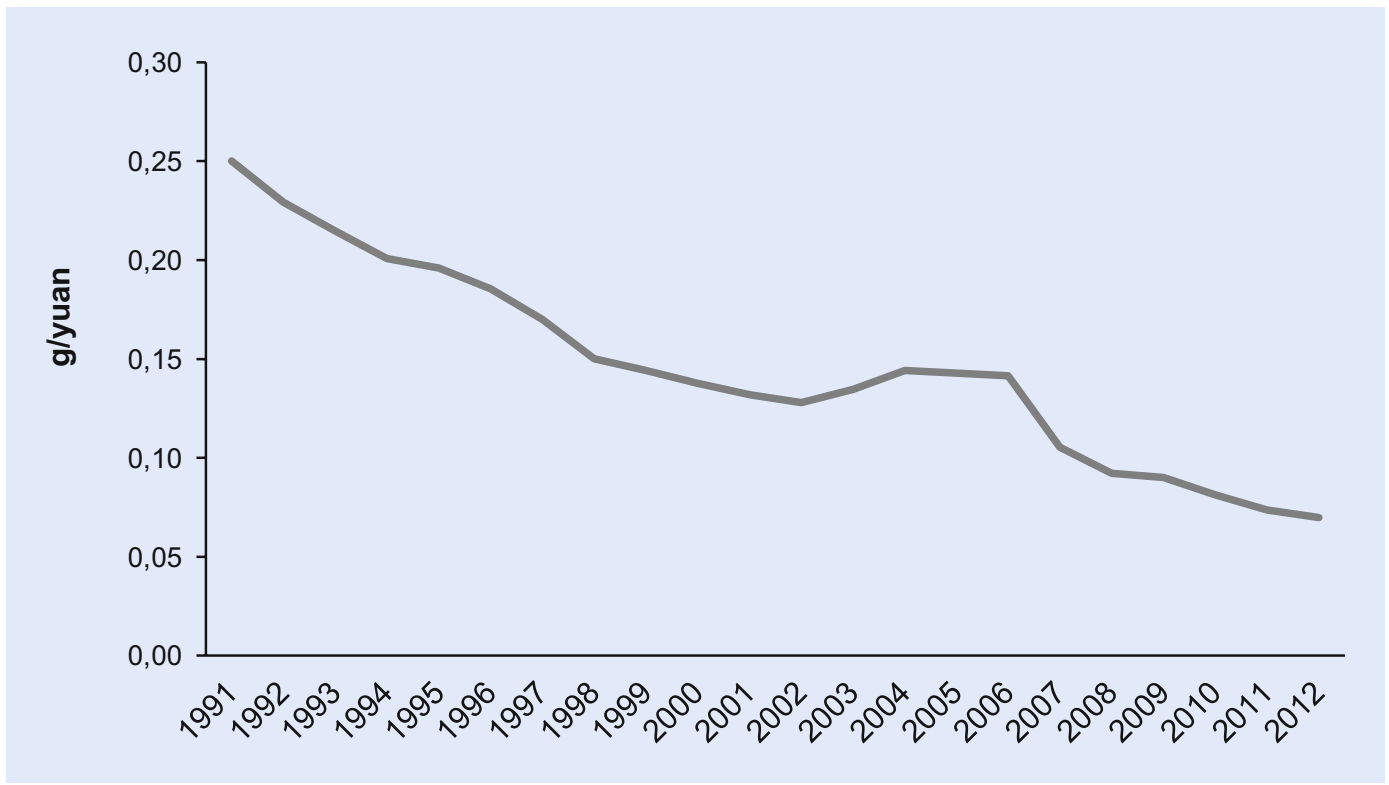

- Fig. 3.4 Energy intensity per unit of GDP (1991-2011), data from [10]

- The high proportion of large coal-fired power plants and lack of gas-fired generators makes the Chinese power system less flexible. At the same time, an increasing share of electricity generated from intermittent renewable energy is increasing the demand for system flexibility.

\subsubsection{Power consumption}

Since the $1980 \mathrm{~s}$, the increase in China's power consumption has been mainly driven by industrial growth. In 2011, more than $70 \%$ of China's electricity was consumed by the industrial sector [15]. The residential sector accounted for approximately $12 \%$ and the commercial sector for $3 \%$ (see $\bullet$ Table A.1 in the appendix). One reason for the high proportion of industrial loads in China is the focus on producing and exporting energy-intensive materials and goods [7]. While it is still relatively high in comparison to countries with a focus on less energyintensive sectors [16], China’s overall energy intensity of production (defined as energy consumption per unit of GDP) has been decreasing consistently due to a number of government measures to promote energy efficiency (see $\bullet$ Fig. 3.4).

China's economy is gradually shifting away from heavy industry towards high value-added industries, such as information technologies and the service sector [12]. The composition of the electricity consumption is projected to change in the coming decades. Shares of residential and commercial electricity consumption are expected to increase. As a consequence, a predicted increase in load variability and range of fluctuation will soon require a higher flexibility of electric power generation [12]. In addition, industrial demand for reliable and high-quality electricity is expected to increase due to the growing importance of information technology in all economic sectors.

\section{Challenges in China's power consumption} sector

- The efficiency of energy and electricity use is low.

- Future energy demand from high valueadded industries will require high power quality and reliability. Also, future demand 
will be more variable in nature, thus requiring a higher degree of flexibility in the Chinese power system.

- There is a mismatch between the current power generation system with its limited flexibility and an increasing demand for flexible generation due to a projected shift in electricity consumption patterns towards more variability in demand.

\subsubsection{Power logistics}

Disparity between power generation and consumption Coal supplies are mainly located in the northwestern, northern, and northeastern parts of China (sometimes referred to as "Three Norths"). Similarly, wind resources are concentrated in the three northern regions as well as along China's coast. Solar energy resources are abundant in the west and north of China. Hydro power is concentrated in the southwest and in the upstream areas of the Yellow River. While energy resources are most abundant in China's north and west, regions that are typically remote and less economically developed, the load is concentrated in the economic and industrial centers along China's eastern coast. This discrepancy presents a major challenge for power logistics (transmission) as well as for the physical transportation of fossil resources and puts a heavy strain on power grid and road/railway infrastructure.

Grid infrastructure The regional disparity between energy resource distribution and load profile on the one hand and between the geographical location of electricity generation facilities and major centers of consumption on the other means that electricity has to be transported from north to south and from west to east. However, China does not have a nationally integrated electricity network. Its network is fragmented into six regional grids with limited interconnection operated by three grid companies: SGCC, China Southern Power Grid (CSG) and the Inner Mongolia Grid Company (for a more comprehensive overview of China's power lines please refer to Table A.2 in the appendix).
Aside from the limited capacity of interconnectors between the regional networks, interregional electricity trade is also heavily impeded by administrative barriers. Regional grids are made up of provincial grids, where dispatch decisions are made with the aim of balancing supply and demand within the boundaries. For cross-border power trading, provinces have to conclude bilateral contracts specifying the annual amount of electricity transmitted in each direction typically netting close to zero [17]. This way of restricting interregional trade makes it difficult to leverage the power system's inherent flexibility potential across regional borders, e. g. the use of dispatchable hydro power capacities for peak generation and ancillary services in other regions [12].

Around the turn of the century, in an effort to speed up nationwide grid integration and to connect regions with significant hydro power, solar, and wind capacities with the load centers on the east coast, China started to construct Ultra High Voltage (UHV) power transmission lines. Today, China is considered a global leader in UHV transmission and transformation technology [18]. Specifically, UHV alternating current (AC) lines are used for transmitting electricity generated in coal-fired power plants or by means of RES from China's northern and western regions to the load centers. UHV direct current (DC) lines are used for transmitting hydro power from South and Central China to the east coast.

Asset utilization and supply security Compared to other countries, for instance the United States, average utilization rates of the grid infrastructure in China are low in spite of the rather flat load curve [19]. Major transmission lines, for example, seldom reach a high utilization rate. In 2011, for instance, two $800-\mathrm{kV}$ lines for which data are available reached utilization rates of less than $35 \%$. Only five of eleven trans-regional lines with $500-$ and $660-\mathrm{kV}$ achieved utilization rates above $50 \%$ [20]. At the level of distribution grids, average utilization rates of $10-\mathrm{kV}$ lines and transformers are even lower and only seldom reach values above $30 \%$ [19].

In principle, low utilization rates point to a large margin for grid operation often resulting in a high level of system stability and security. In the specific case of China, average annual outage times of urban 
users during the last years exceeded seven hours (see - Table A.3 in the appendix) and those of rural users even ten hours [19]. In Germany, to give a reference value from an industrialized country, average annual outage times were only approximately $15 \mathrm{~min}$ utes in 2010. This evidence points to low levels of equipment maturity in parts of the electric power grid (see also [21], [22]). In recent years, investments in distribution grids have been considerably smaller than those in transmission grids [12]. Most line losses and power outages in China occur in the distribution grid [19] pointing to less sophisticated equipment in the distribution grid compared to the transmission grid (see also [21]).

Investment needs in the grid infrastructure In the coming years, massive investments will have to be made in the electric power grid in order to cope with the steadily rising power consumption, increase supply security, and facilitate the integration of wind and PV power. It is projected that, in 2020, the total length of power lines of $110 \mathrm{kV}$ and above will reach 1.76 million kilometers with an associated transformer capacity of 7.9 billion kVA [23]. This represents a considerable increase compared to line length and transformer capacities in 2010 (see Table A.2 in the appendix).

\section{Challenges in China's power logistics} sector:

- The regional disparity between power generation and consumption in combination with barriers to interregional electricity exchange imposes a constraint on the efficient use and delivery of energy resources.

- The barriers to interregional electricity exchange make it difficult to fully exploit the flexibility potential inherent in the power system.

- Asset utilization rates of China's electric power grids are below those of highly industrialized countries such as the United States in spite of China's rather flat load curve.

- Supply security in China is considerably lower than in highly industrialized countries. There is evidence that a large part of power outages and line losses in China originate from distribution grids. This indicates that distribution grid equipment is less mature and sophisticated than transmission grid equipment.

\subsection{Smart grid development in China}

\subsubsection{Motivation for smart grids in China}

Smart grids for increasing supply security A core motivation for smart grids in China is their suspected positive impact on supply security. In China, especially distribution grids with voltage levels of $10-\mathrm{kV}$ and less are limiting reliability for urban end-user's, causing roughly $80 \%$ of all power blackouts [19]. Due to missing sensoring and monitoring technologies, it often takes a long time to analyze the respective line, locate and isolate the fault, and re-establish electricity supply [19].

Enhancing distribution grids with smart grid technologies such as advanced sensoring and control technologies is often seen as a means to improve the reliability of the whole electric power system in China (see e.g. [19]).

Smart grids for facilitating peak shaving The rapid growth of electricity consumption reflected in very high peak loads may cause shortages on the generation side and network congestions. Also, the rising importance of residential electricity consumption compared to industrial electricity consumption will lead to a more pronounced load curve. This trend could be further accentuated by China's continuing urbanization process [24]. With low gas generation capacities and limited transmission capacities, coal-fired power plants are mainly employed for load-following and peak generation in China. This reduces their operational efficiency. Peak shaving is of critical importance as it contributes to a reduction of peak loads and thus helps to avoid peak generation. Peak shaving might also reduce potential network congestions when demand 
peaks occurring in periods of network congestions are reduced via demand side management. As such, it should be seen as an important factor towards a more reliable power system in China. In addition, by reducing the maximum grid load, peak shaving helps to increase average utilization rates of the grid infrastructure, thus reducing investment needs and increasing the affordability of electricity supply.

To enable peak shaving and demand side management it is necessary to deploy an ICT infrastructure for two-way communications between endusers - or so-called prosumers if they also generate electricity - and grid operators. Together with other smart grid technologies facilitating real-time data exchange, visualization of information as well as control of devices, this infrastructure enables the grid operator to have a clear picture of electricity consumption and generation at any given time, while allowing endusers to receive price signals to adapt their electricity consumption to the variable supply.

Smart grids for preparing extensive integration of RES China has aggressively expanded RES generation capacities within an extremely short time frame. Grid connection of RES is currently lagging behind and a considerable amount of RES-E is curtailed. In this context, smart grid technologies are often seen as a means to reduce RES integration costs:

- Large-capacity battery storage systems facilitate the integration of centralized large-scale intermittent RES generation capacities of the type that are currently focused upon in China. ${ }^{1}$

- Due to frequent network congestions at the local level, a considerable quantity of electricity generation from RES has to be curtailed. More effective grid capacity management using smart grid technologies could reduce curtailment of RES.

- Smart grid technologies such as microgrids and virtual power plants ease the integration of RES at the local level.

1 One example for the trend towards large-capacity battery storage are the activities of BYD. The Chinese manufacturer of automobiles and rechargeable batteries built one of the world's largest lithium-ion battery energy storage systems, a 36-megawatt-hour system, located in Zhangbei, Hebei [52].
- The grid connection itself might be more effective with smart grid technologies. One aspiration expressed in this area is that RES might be integrated into grid operation via standardized ICT connectors so that the integration of standard RES plants might become as easy as connecting external devices with computers via universal serial bus (USB) interfaces (plugand-play integration) [25].

\subsubsection{China's technological view of the smart grid}

The development of smart grids in China An early form of smart grids was proposed in 1999 by $\mathrm{Lu}$ and Mei [26] in their article Basic research on vital scientific problem with collapse prevention and optimal operation of large scale power systems [27]. Five years later, distributed computing was applied in a research project for a real-time simulation of the entire power grid [27]. In 2007, the East China Grid Company, a subsidiary of SGCC, carried out a feasibility study on smart grids that examined the promotion of digital substations and build-up of a unified enterprise platform for power system data [27].

The grid operator's view on smart grids Since then, China's smart grid development has mainly been pushed forward by China's grid operators, SGCC and CSG. In 2009, SGCC proposed the strategic goal of building strong and smart grids with Chinese characteristics. SGCC focuses on the nationwide integration of provincial and regional grids by means of a strong UHV AC backbone. The first objective of this backbone grid is to ease the balancing and power exchange between different regions, the second to integrate large-scale generation from RES. CSG, on the other hand, envisages a smart grid with a more decentralized focus using primarily high voltage direct current (HVDC) links as backbone systems. CSG intends to integrate remote energy sources, especially hydro power. HVDC development will lead to separated asynchronous provincial grids. The nationwide synchronization of China's power grids is not one of CSG's main goals. Comparing both strategies reveals that the two grid 


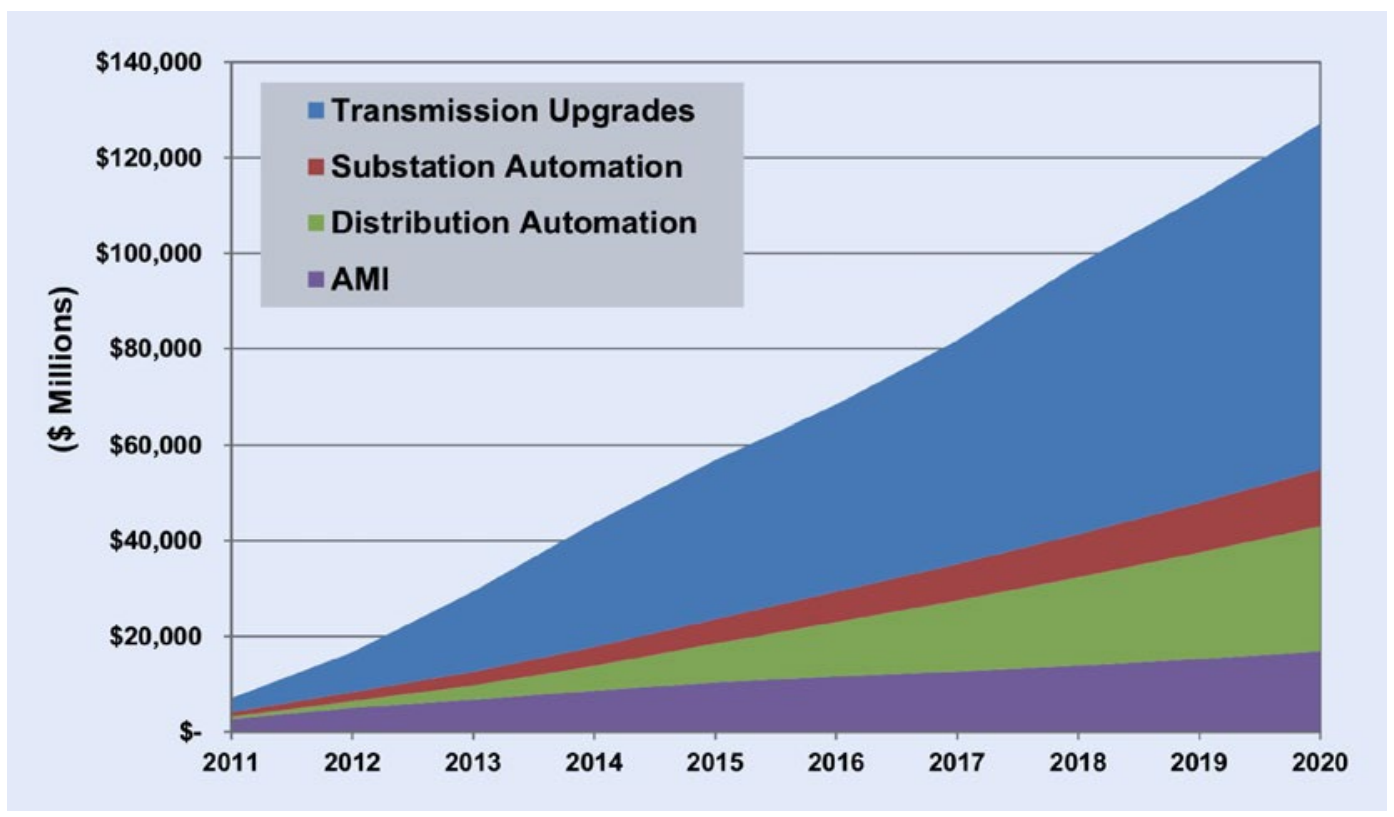

- Fig. 3.5 Annual overall smart grid revenue of main smart grid technologies in China (๑ Navigant Research [28])

operators pursue different approaches with regard to the type of transmission technology and the nationwide synchronization of China's power grids.

In spite of this disagreement, the smart grid visions of both grid operators concentrate mainly on the upgrade of transmission grids: a look at the total annual smart grid revenues from the most important smart grid technologies in China reveals that currently more than $50 \%$ of revenue is related to upgrades of transmission grids. Substation and distribution automation technologies are responsible for no more than a low share of overall smart grid revenues (see - Fig. 3.5). According to markets forecasts for 2020, the absolute increase in smart grid revenues related to transmission upgrades is significantly higher than the increases of revenues from substation automation, distribution automation, and AMI (see • Fig. 3.5).

The government's view on smart grids China's government has already acknowledged the importance of smart grids for China's future energy system. In its $12^{\text {th }}$ Five-Year Plan for National Economic and Social Development, the People's National Congress explicitly set the goal of accelerating smart grid developments in China (see [27]). In the Decision of the
State Council on Accelerating the Fostering and Development of Strategic Emerging Industries, the State Council also underlined the importance of speeding up the development of smart grids (see [27]).

In addition to the general commitment to smart grids, NEA also issued a general definition of smart grids:

॥ Smart grid technologies have the purpose to integrate new energy, materials and equipment as well as advanced technologies in information, automatic control and energy storage for realizing digital management, intelligent decision-making and interactive transaction in power generation, transmission, distribution, consumption and storage. Furthermore, smart grid assets optimize the resource allocation and satisfy diverse needs of customers as well as ensure the safety, reliability and cost-efficiency of power supply. Finally, the new technology [in the sense of smart technology] bridges the constraint of environmental protection and the development of the power market.

Moreover, the Chinese government supports the technological development of main smart grid technologies by means of innovation policies 
such as standardization and $\mathrm{R} \& \mathrm{D}$ funding (see - Sect. 3.4.6). However, in contrast to both grid operators, the Chinese government has not yet developed a perspective of its own on the technological and organizational design of China's smart grids. As a result, the discussion of such aspects is still dominated by the grid operators and there is currently no unanimously accepted comprehensive view of smart grids in China.

This lack of common understanding among the main stakeholders is the cause of many controversies and basic disagreements on the key aspects of smart grid development [27]. The absence of such a common vision increases uncertainty for potential smart grid investors because the profitability of their investments critically depends on whether a strong and smart or a decentralized smart grid will be realized. Thus, the lack of a comprehensive smart grid vision has to be viewed as an obstacle towards the development of smart grids in China [27].

Main challenges with regard to the technological view of smart grids

- Due to the contrary strategies of China's grid operators on the subject of smart grid development and the absence of a Chinese government view on smart grids, there is still no unanimously accepted vision on the technological and organizational design of smart grids in China. As a result, there is much uncertainty among potential smart grid investors regarding the future development.

\subsubsection{This study's view on smart grids in China}

The present study has a clear focus on proposing regulatory policies supporting the evolution of smart grids in China. The creation of a widely accepted technological smart grid vision is beyond the study's scope. Nonetheless, a common understanding of desirable smart grid developments during the next years is necessary to determine the general direction of the regulatory recommenda- tions. Given the missing unanimously accepted smart grid vision in China, a pragmatic three-sided approach was employed to develop such a common understanding:

- Following a bottom-up approach, China's future smart grid is considered to comprise a broad portfolio of ICT together with various modern technologies for power generation, transmission, distribution, storage, and consumption. ${ }^{2}$ This also includes modern grid technologies such as UHV transmission grids or heat-resistant wires. A recent literature review supports this view by underlining that smart grids in China focus on all sections of the power system, including smart power generation, transmission, deployment, usage and storage. Specifically, the integration of RES should also be understood as part of the topic of smart grids in China [27].

- The smartness of the current electric power grid as well as the desirable smartness of the power grid in 2020 was assessed. In particular, the current levels of system integration of single power system components as well as the projected levels in 2020 were described. In this context, system integration refers to the extent to which power plants, wind farms, transmission grids, distribution grids, and power consumers are expected to be remotely monitorable, controllable, or even autonomously controllable (self-healing). ${ }^{3}$

- Given the government's will to establish energy markets, the study compares market elements used in China today with those projected for $2020 .^{4}$

This three sided-approach has led to the following conclusions:

- China has in recent years made important breakthroughs in the development of smart grid technologies. Examples for such technolo-

2 Please refer to appendix B for a complete overview of all modern technologies that are subsumed under the smart grid label in this study.

3 Please refer to appendix $C$ for a complete overview of the results.

4 Please refer to appendix $C$ in for a complete overview of the results of this discussion. 
gies are UHV transmission grids and largecapacity battery energy storage technology. ${ }^{5}$

- On the other hand, a big leap forward with regard to many smart grid technologies is indispensable at all stages of the smart grid supply chain. ${ }^{6}$ Like in many other countries engaged in the development of smart grids, some of China's key smart grid technologies are still immature and have somewhat inconsistent component specifications and standards [21], [22], [27].

- In 2020, market elements such as regional energy marketplaces and virtual power plants are intended to be used much more intensively than today. They will be introduced at least on provincial level.

With the study's focus on regulatory issues in mind and in light of the conclusions described above, the regulatory pathways presented in this study aim specifically at:

- facilitating the widespread deployment in 2020 of those smart grid technologies which have already achieved high maturity levels today. In this context, smart grid technologies also include modern grid technologies which are not necessarily included in smart grid concepts of other countries;

- promoting technological innovations of rather immature smart grid technologies and increase their maturity;

- promoting the development of so-called smart markets (see - Sect. 4.3.2 for more details on smart markets). In this context, an important prerequisite is the integration of third parties. They are seen as key players in smart markets.

5 Please refer to appendix B for a complete list and description of these technologies.

6 Please refer to appendix C for an overview of the necessary technological advancement during the next years.

\subsection{The regulation of China's electric power system}

\subsubsection{Policy setting and fundamental institutions}

\section{Policy Setting}

Government leadership is essential to promote smart grid development. The general strategy of policy-makers towards the development of the future power system, often containing quite specific targets for short-term and long-term development, is important for companies and other stakeholders in the electric power sector: indeed, this government strategy serves as an important basis for smart grid investment decisions of both companies and households.

The Chinese government has set quite specific targets with regard to the development of the energy system until 2015. However, there are no explicit targets beyond this point in time. The most important government targets for 2015 are briefly summarized below:

- From 2010 to 2015, generation and grid capacities are planned to increase by roughly $50 \%$ in order to cope with the steadily growing demand.

- RES generation capacities are expected to increase out of proportion - their share in the electricity mix will increase significantly.

- Average utilization rates of the grid infrastructure and supply security are targeted to increase. Specifically, power outages on the level of distribution grids, are expected to be reduced.

- The efficiency of energy use and particularly of electricity use is planned to improve considerably.

A detailed overview of government targets for China's future electric power sector is given in - Sect. 6.1 in the context of the regulatory pathways.

\section{Fundamental institutions}

To realize the government agenda, ministries and other government institutions issue laws and ordinances, monitor compliance with these laws and ordinances, propose major technological standards, 
and promote innovations. The question regarding whether the different government practices can be executed effectively largely depends on the governance structure of ministries and government institutions.

Governance structure The governance structure of China's energy system, and in particular the power sector, has been subject to frequent reorganization and currently comprises a broad variety of ministries and institutions. The fragmentation of responsibilities among a multiplicity of different stakeholders makes conflicts of competence inevitable and a coherent and continuous governance of the power sector difficult [2].

- Figure 3.6 presents a graphical overview of the main authorities of China's power sector governance (- Table A.4 in the appendix further specifies influences, roles, and responsibilities of main governmental institutions). There are four main government authorities involved in China's power sector policy:

- The State Council (SC) is the highest executive organ of the People's Republic of China. With regard to the electricity sector it sets the political agenda, takes the lead for major reforms and is in charge of promulgating major plans like the Five-Year Plan for energy development.

- The NDRC is an agency under SC exerting broad administrative and planning control over the Chinese economy. It is the most important government authority for power sector regulation. Its powers include the regulation and setting of energy and electricity prices, the approval of major power sector projects, as well as energy efficiency policy.

- The NEA proposes the energy development strategy, drafts energy development plans as well as energy-related policies, provisions and laws to be adopted by NDRC or SC. NEA also advises on power system reform and market regulation. In addition to these political functions, NEA is the regulatory authority for the power sector in charge of regulating power system construction, power safety, power supply and service, as well as tariff and information disclosure.
- The State-owned Asset Supervision and Administration Commission of the State Council (SASAC) supervises the performance of SOE such as the grid operators and the major power generation companies. SASAC exerts its power through the right to appoint, dismiss and evaluate the performance of executives, the right to audit as well as to approve key decisions.

The existing literature on China's governance structure in the electric power sector (see for example [2], [3], and [30]) often stresses several regulatory challenges potentially preventing an effective development towards smart grids in China:

- There is a significant fragmentation as well as overlap of responsibilities of the various government bodies involved in power system regulation, negatively affecting the efficiency of the sector's governance.

- In international comparison, China's major institutions governing the energy sector have a rather low number of employees, staff numbers not always being adequate to fulfill the responsibility of regulating an electricity system the size of China.

- The importance of the previous aspect even increases when the size and the power of China's major grid operators are taken into account. The grid operators' stakes are so high that it always pays off for them to hire consultants, lawyers, and lobbyists to argue their case. To address these claims, the regulator needs to be equipped with a sufficient number of highly qualified employees.

- Essential instruments to steer power sector development, like electricity pricing, remain under the authority of NDRC. The concentration of power within NDRC limits the ability of NEA to drive power sector reform.

Regulatory challenges in the area of policy setting and fundamental institutions

- Efficient governance of the power sector is impeded by overlapping responsibilities and conflicts of interests between different government authorities. 


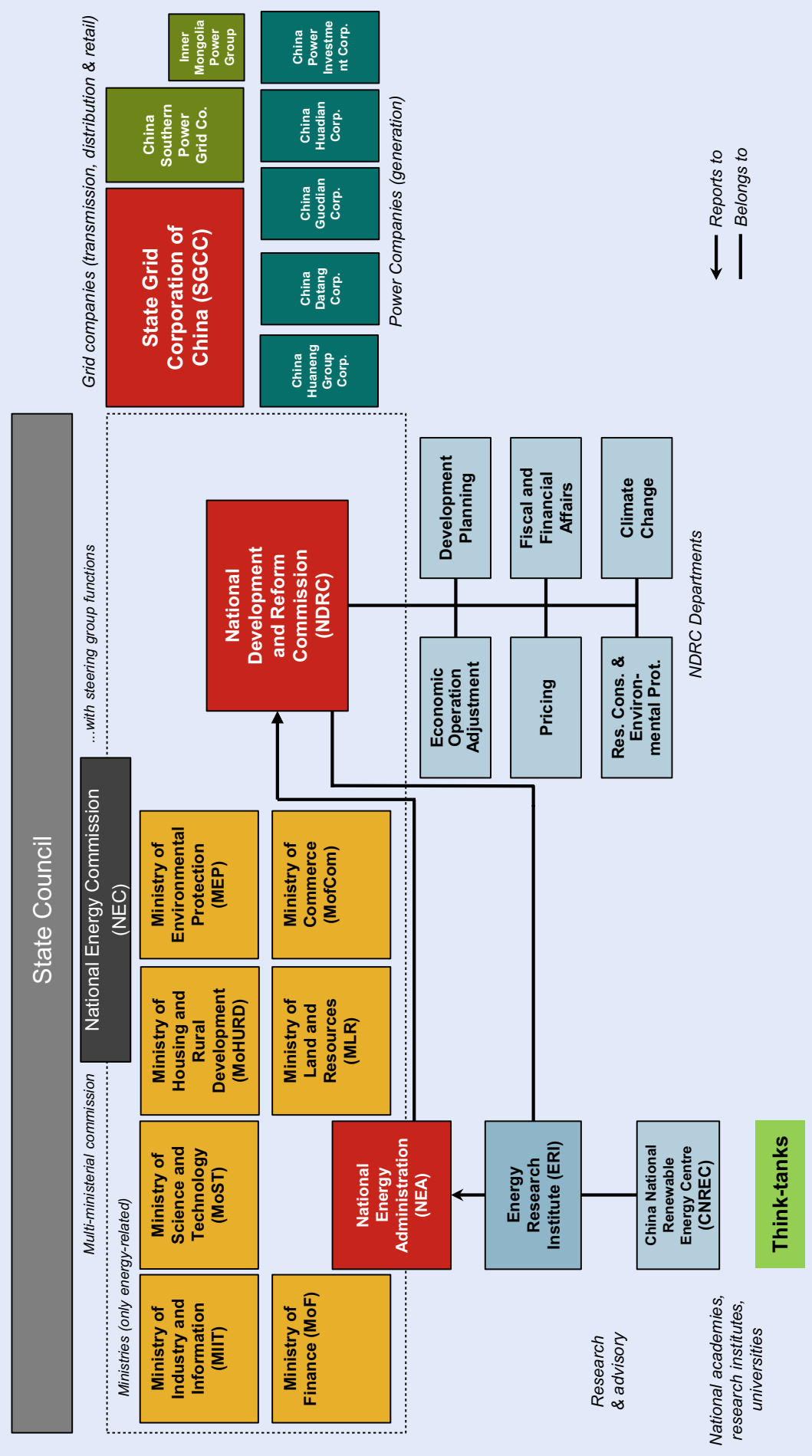


- In international comparison, NEA is understaffed, underfunded and without sufficient power to make independent decisions. The lack of independence and law enforcement authority has a negative effect on regulatory performance.

- The concentration of power within NDRC limits the ability of NEA to drive power sector reform.

\subsubsection{Market structure}

The market structure and especially the involvement of new market actors is a critical factor with regard to the innovation potential in the smart grid development process. The following paragraphs will describe the governance structures between the companies at the various stages of the supply chain (vertical market structure) and the competitive conditions for the companies in each part of the supply chain (horizontal market structure).

Vertical market structure The competences and responsibilities of China's power system supply chain have been tightly bundled over a long period of time. The main electricity sector reform of 2002 mandated the separation (or unbundling) of the state-owned vertically integrated utility into five big power generation companies, two major grid operators handling transmission, distribution and retail as well as four power service corporations.

All of them are SOE. Under this market structure, the grid operators are assigned regional monopolies acting as single buyers from generation side as well as being the only seller with the electricity retail monopoly within their geographic area.

Horizontal market structure In the field of power generation, the five major power generation companies, the so-called Big Five are responsible for roughly $50 \%$ of China's electricity generation. By means of its project approval process, NDRC tries to balance generation capacities between them [31]. Due to their size, the Big Five have a significant lobbying force contributing to China's power system governance together with the government and the grid operators. The remaining part of China's power is generated by thousands of smaller local and regional generation companies. In addition, there are specialized generation companies mainly focusing on power generation from one energy source, e.g. hydro or nuclear power. China's power generation sector can be described as liberalized, as it potentially allows competition between the different companies. However, compared to local governments or state-owned companies, private and foreign investors still face significant legal and administrative barriers restricting the development of a diverse ownership structure [2].

Power transmission, distribution and retail are currently vertically integrated and operated by two major SOE with geographical monopolies including electricity retail: SGCC controls the eastern, central, northwestern, northern and northeastern grids; while CSG is in charge of the southern grid. In the sparsely populated province of Inner Mongolia, an independent grid operator, the Inner Mongolia Electric Power Corporation, controls the western part of the grid while SGCC controls the eastern part. Due to their importance for the development of China's power system, both SGCC and CSG are briefly introduced below:

\section{- State Grid Corporation of China (SGCC), an} SOE, is the $7^{\text {th }}$ biggest company in the world according to the 2012 Fortune Global 500 list, with almost 1.6 million employees [32]. SGCC is responsible for power transmission, distribution, and retail in all five major regions of China with the exception of South China. Its operations cover 26 provinces, autonomous regions and municipalities $-88 \%$ of the national territory - and $83 \%$ of the national power consumption [33] (see $\bullet$ Table A.5 in the appendix for a list of affiliated grid operators). The company has ministry-like status and is a powerful force in power sector governance [34].

- China Southern Power Grid (CSG), also an SOE, ranks at position 152 on the Fortune Global 500 list and has roughly 300,000 employees. CSG is responsible for power transmission, distribution, and retail in the five provinces of South China, covering $12 \%$ of 
the national territory and $17 \%$ of the national power consumption [33].

Both grid operators are currently expanding their business portfolios across the value chain: SGCC has taken over domestic engineering firms and leading electric power equipment manufacturers, raising concerns about conflicts of interests and a threat to competition due to the concentration of multiple roles within one company (i. e. roles standard setting, manufacturing equipment, transmitting and selling electricity).

At the same time, SGCC is pursuing a "going global" strategy targeting the acquisition of assets abroad [35]. The advancing vertical integration of SGCC has caused discussion as to whether its mergers and acquisitions go against China's power sector reform policies of downsizing and unbundling grid operators. Recently a potential separation of grid operators into transmission and distribution companies or into smaller, regional businesses has been subject of debate [34].

\section{Regulatory challenges in the area}

of market structure

- Transmission, distribution and retail of China's electricity are in the hands of two grid operators. There is no competition in the power retail sector.

- The acquisitions of grid operators in other segments of the value chain (e. g. equipment manufacturing and services) threaten fair competition in these sectors.

- The size and power of grid operators makes it difficult to regulate them.

\subsubsection{Market design and RES integration}

The question regarding how electricity markets are designed is highly important for the development of smart grids because market design affects electricity pricing. Pricing mechanisms, including feed-in tariffs for RES, are of crucial importance with regard to the utilization of different generation sources, investment decisions for new generation and grid capacities, day-to-day power consumption patterns, and investments in power saving technologies.

General market design Prices for energy resources, power system equipment and electricity were fixed by the government for a long period of time. In the $1980 \mathrm{~s}$, the government started to gradually liberalize coal prices. Coal is currently at least partly traded at variable market prices, either depending on spot market rates or on individually negotiated contracts [31].

Irrespective of market liberalization tendencies, China still lacks a formal and transparent mechanism for linking real costs and prices of electricity [12]. Electricity markets with prices based on supply and demand do not exist in China. Two types of electricity prices exist in China:

- On-grid prices are the prices power generators receive from their grid operator for each $\mathrm{kWh}$ generated.

- Retail prices are the prices grid operators (which are also responsible for retail) charge to end consumers for each $\mathrm{kWh}$ consumed.

Both prices are fixed by the price department of NDRC and adjusted every 18-24 months. ${ }^{7}$

Setting on-grid prices NDRC determines on-grid prices for power generation using two different approaches:

- On-grid prices for thermal generators are set using a price benchmark for generators within the same technology class. Each power plant is contractually guaranteed a certain capacity factor (number of full load hours) equal to comparable facilities. The equal capacity factor is based on an estimate of annual power output as well as on average fixed and variable costs.

- On-grid prices assigned to owners of hydro power and nuclear power plants differ from facility to facility. They are the sum of the

7 Jointly with local and provincial price bureaus, the price department of NDRC is responsible for the formulation, inspection, approval and establishment of the tariff, as well as for the supervision and inspection of the tariff implementation. In addition to NDRC, the NEA may put forward suggestions to the price department of NDRC. 
plant's generation costs, governmental taxes and surcharges, and profits attributed to the plant owner [2] [12].

To give a short overview of the results of these price-setting mechanisms, the following list shows on-grid prices for electricity stemming from different conventional generation technologies in 2012 (prices from [31]):

- Gas-fired power plants:

0.395-0.710 RMB/kWh

- Coal-fired power plants:

0.311-0.520 RMB/kWh

- Nuclear power plants:

0.414-0.471 RMB/kWh

- Hydro power plants:

0.145-0.411 RMB/kWh

Consequences of on-grid price setting Both price setting approaches ensure that plant operators usually earn revenues sufficient for the repayment of their investment costs within one decade [2]. That is, in principle, both approaches are sufficient to incentivize investments in power generation capacities. However, such price setting approaches based on costs are often viewed quite critically in the economic literature (see e.g. [36], [37], and [38]): for example, they are quite time-consuming for the regulator. In China, the following aspects have to be emphasized with regard to the setting of on-grid prices:

- Due to the fact that coal prices are flexible while on-grid electricity tariffs for coal-fired power plants are strictly regulated and adjusted rather infrequently, power companies are not able to directly pass on changes in fuel costs. During periods of high coal prices, power companies have seen their revenues squeezed to such an extent that they have restricted generation in order to limit their losses. This behavior further aggravates the problem of missing generation capacities and contributes to the emergence of power outages.

- The approach used to set on-grid prices of hydro power and nuclear power plants gives few incentives to save costs, because potential cost savings in one specific power plant would lead to lower on-grid prices for the plant within 18-24 months. Even more, such approaches give an incentive to exaggerate generation costs by means of creative financial accounting to receive higher on-grid prices [38].

Setting of retail prices Retail prices are amended from province to province to account for policy goals and status of economic development. They are also differentiated according to end user groups. The current national averages of electricity retail prices for different consumer groups are:

- Commercial: 0.863 RMB/kWh,

- Non-residential lighting: $0.791 \mathrm{RMB} / \mathrm{kWh}$,

- Industrial use: $0.698 \mathrm{RMB} / \mathrm{kWh}$,

- Residential: $0.498 \mathrm{RMB} / \mathrm{kWh}$,

- Agriculture: $0.419 \mathrm{RMB} / \mathrm{kWh}$,

- Irrigation in poor areas: 0.201 RMB/kWh.

Retail tariffs are subject to cross-subsidization in certain market segments to account for differences in income and to ensure social stability. Tariffs for residential, agriculture, irrigation and drainage use, together reflecting about $20 \%$ of the Chinese power consumption, are lower than average generation costs. It is notable that industrial users generally pay higher tariffs than households.

Consequences of retail price setting The main disadvantage of low retail prices is that a low price level does not incentivize consumers to use power more efficiently. There is evidence that residential electricity consumers in China are quite sensitive to changes in electricity price levels [39]. Thus, increasing electricity prices would probably lead to significant reductions of electricity consumption among Chinese households. However, increasing electricity prices for residential consumers is not a political option in China given the government's intention to keep prices for residential consumers low. Therefore, China currently employs a number of other retail pricing policies that serve to align economic and environmental targets of the electricity sector [1]:

- A three-tiered pricing system has been applied to residential consumers since mid-2012. Electricity prices are set in blocks with higher rates for customers with a large electricity consumption (referred to as inclining block pricing).

- In addition, China has implemented a policy differentiating the electricity tariffs based on 
the energy efficiency of industrial processes. The policy, which is applied to eight energy-intensive industries, aims at phasing out outdated industrial capacities or incentivizing upgrades.

Promotion and integration of RES Feed-in tariffs have proven to be an efficient instrument to promote RES in China. They are paid to RES generation installations depending on the type of renewable energy and location of the installations. Feed-in tariffs for RES generation are considerably higher than on-grid prices for hydro power and coal-fired power plants. In 2012, the ranges for feed-in tariffs of different RES generation types in 2012 were [31]:

- Solar: $1.00 \mathrm{RMB} / \mathrm{kWh}$

- Biomass: 0.56-0.77 RMB/kWh

- Wind: 0.51-0.61 RMB/kWh

The Renewable Energy Law obliges grid operators to feed in renewably generated electricity. The resulting costs are socialized through a renewable energy surcharge levied on all electricity users in China [31]. ${ }^{8}$ Since the initial publication of the 2006 Renewable Energy Law, the renewable energy surcharge has been adjusted three times, with the last increase from 0.008 to $0.015 \mathrm{RMB} / \mathrm{kWh}$ taking place in September 2013. To ensure that the grid companies do not misuse the surcharge, it is turned over to the Ministry of Finance (MOF) in a first step. The grid companies then apply to MOF and NEA for the disbursement of these funds with supporting documentation [40]. This procedure causes a delay in the reimbursement of grid operators' expenses for purchasing power generated from renewables, which in turn results in a lack of operating capital with serious effects on the whole supply chain. Grid operators delay payments to wind power developers, who in turn are unable to pay renewable energy equipment manufacturers (e.g. wind turbines), resulting in delayed payment of component suppliers. This situation is expected to be alleviated with the recent doubling of the renewable energy surcharge. From the grid operator's perspective, delays in reimbursement may be seen as a reason to delay the grid connection of renewable energy generators.

8 Note that agricultural uses and power consumers in Tibet are excepted from the surcharge [43].
Regulatory challenges in the area of market design and RES integration

- On-grid and retail electricity prices do not reflect actual costs and are adjusted only infrequently.

- The approach used for setting on-grid prices of hydro and nuclear power plants gives only few incentives for cost savings. Rather it gives incentives to exaggerate costs to achieve a higher on-grid price.

- Although a system of tiered prices has been introduced for residential consumers, the low overall level of retail electricity prices does not provide sufficient incentives for consumers to use power more efficiently.

- Delays in the disbursement of RES funds leads to a lack of operating capital along the renewable energy value chain and provides a disincentive for grid operators to connect RES plants to the grid.

\subsubsection{Development of infrastructure and network regulation}

This section explains how grid planning is done in China and how investments in the (smart) grid infrastructure are incentivized. The pertinent regulatory practices directly impact the stable and affordable operation of the current grid infrastructure and the investments in the prospective smart grid infrastructure.

Network expansion planning The government's key target is cost-efficient extension and development of the power grid in order to cope with the steadily increasing electricity consumption and minimize supply interruptions.

Targets on the development of grid infrastructure and grid operators' performance are specified by the government in a top-down process. However, little information is publicly available on official grid expansion plans [41]. As a result, the document Framework and Roadmap for Strong and Smart Grid Standards, published by SGCC in 2010 [42], serves as an unofficial (smart) grid development plan in 
China [41]. With respect to grid expansion planning, there is little guidance from the government and little coordination among existing power system stakeholders.

Network regulation At present, there is no explicit price for transmission and distribution (network charge) based on actual costs. The source of grid operators' income is the difference between the on-grid and the retail price for electricity. This amount covers all costs of the grid operators: grid operation and maintenance, grid upgrade and expansion, management, metering and billing, etc. The remainder makes up the profits of the grid operator. The government targets a rate-of-return for the grid operators in the range of about 8 to $10 \%$ [43]. This practice, in combination with the rather infrequent adjustments of the retail electricity tariffs, has an impact on the ability of grid companies to quickly and predictably recoup costs. In turn, the grid companies may exhibit little motivation to invest and assume costs related to the implementation of government policies and regulations, e.g. for investments related to renewable grid connection and integration, investments in end-use energy efficiency or distributed generation [1]. Moreover, the cost structure of power sector companies lacks transparency and power sector data and information available to the public is very limited. Opaque costs affect the government's ability to regulate and inform the setting of electricity prices.

There are no clear rules for accounting of costs, revenues, and profits and no transparent administrative process for setting allowed revenues. Without this foundation the government is unable to audit companies' accounting records or exact penalties for noncompliance with reporting obligations, information requests or other government requirements [1].

Regulatory challenges in the area of development of infrastructure and network regulation

- Grid expansion planning is organized in a top-down process with low transparency and little involvement of players other than government authorities and grid operators.
- The price-setting mechanism with respect to wholesale and retail prices together with the rather infrequent adjustments of retail prices reduces the ability of grid companies to quickly recoup costs. This might reduce their willingness to incur costs related to other government policies (for instance related to RES integration).

- A lack of transparency of costs impedes the efficient and informed regulation of power sector companies.

\subsubsection{Coordination of generation and consumption}

The following paragraphs describe general responsibilities for coordinating electricity generation and consumption. Government measures implemented in this context are also presented.

Long-term coordination of generation and consumption China's rapid economic growth has resulted in a steadily increasing electricity consumption. The Chinese government promotes the expansion of generation and grid capacities. In addition, the role of energy efficiency as an instrument to decouple the rise of power consumption from economic growth has been recognized. $\mathrm{Nu}-$ merous policies to promote energy efficiency have been promulgated: for instance, national targets for energy intensity, differential pricing for energy-intensive industries and energy efficiency obligations requiring Chinese grid companies to realize energy conservation targets (e.g. through end-user energy efficiency programs).

Short-term coordination of generation Historically, dispatch of power plants in China is organized by means of a so-called equal shares dispatch or generation quota system. China allocates operating hours equally among the coal-fired generators that constitute the bulk of China's generating capacity. This system is intended to give each generator an equal chance to recover capital costs and achieve a reasonable return-on-investment, but it 
largely ignores the fact that plants within the coal fleet vary significantly in terms of efficiency and environmental performance [44]. Annual operating hours for generators are set administratively by Provincial Economic and Trade Commissions (PETC) and approved nationally by NDRC. As a result, the overall performance of the power system has suffered significantly in terms of cost, environmental performance, and distorted investment decisions. The dependence of each coal-fired generator on running a similar guaranteed number of hours has become a major barrier to reforming dispatch in China.

In 2007, China started to pilot a so-called energy efficient dispatch system. This system sets a dispatch order prioritizing generators on the basis of heat and emissions rates favoring renewable and low carbon generation sources, with coal-fired power plants dispatched according to their thermal efficiency. This order is based on the priority order table created by PETC and is updated quarterly based on changes in generator parameters and the addition of new units [45]. Hence, the power generation quotas of power generation facilities are no longer guaranteed [46]. Since on-grid prices are calculated on the basis of a fixed estimate of annual operating hours, generators will face a revenue shortfall if average operating hours fall below the projected level [44]. One of the main drawbacks of the policy was a lack of compensation of power and grid companies for lost revenues due to the changes in dispatch. The pilot has proved to be difficult to implement and has not spread to the whole country [47].

Regardless of whether a generation quota or an energy-efficient dispatch system is used, the specific day-to-day dispatching is in the hand of dispatch centers under the authority of national, regional, provincial, or local grid companies. The dispatch centers take into account factors like load forecasts, the availability of power plants, and constraints for system reliability. On this basis, the dispatch centers set day-ahead commitment plans for the power plants. Power generation companies are subsequently obliged to supply power as required [44].

Short-term coordination of consumption Like in all other regions of the world, China's intraday power generation follows intraday power demand.
However, early attempts have been made to influence the hourly pattern of China's power consumption and to shift power consumption from peak times to off-peak times: since the $1990 \mathrm{~s}$, many provinces have started to coordinate power consumption by means of interruptible loads and time-of-use prices:

- Interruptible loads refer to a pricing mechanism in which large industrial consumers are paid for curtailing their loads in times of network congestions. This demand response (DR) mechanism has been piloted and regionally applied in China [12].

- Time-of-use pricing means that the electricity price varies depending on the time-of-day when electricity is provided. In times of network congestions prices tend to be high to incentivize electricity consumers to reduce their consumption. With the 2005 Interim Provisions for the Administration of Power Selling Prices, the Chinese government stressed the role of time-of-use prices to reflect real costs at different day times [2]. Time-of-use pricing has been implemented mainly for industrial and commercial users [48]. In some regions, timeof-use pricing is also applied to residential customers. The Chinese government has recently announced that it will introduce time-of-use pricing for residential consumers on a national level by the end of 2015 [49]. Overall, it is still questionable whether the existing incentives are actually sufficient to induce customers to shift electricity consumption to off-peak times [2].

Regulatory challenges in the area of coordination of generation and consumption

- The generation quota system ignores the fact that power plants within the coal fleet vary significantly in terms of efficiency and environmental performance. As a result, the overall performance of the system has suffered significantly in terms of cost, environmental performance and distorted investment decisions. 
- The dispatch model is closely linked to the electricity pricing mechanism; no dispatch reform can be introduced without a reform of electricity pricing, and such a reform would have to compensate coal power plants whose revenue is calculated on the basis of the existing dispatch model.

- China has made remarkable progress with regard to the introduction of time-of-use pricing. Such pricing mechanisms are planned to be applied to all categories of customers in 2015. However, it is unclear whether the specific design of time-of-use prices actually sets sufficient incentives for shifting electricity use among all groups of customers.

\subsubsection{The role of information and communication}

The government's role in promoting smart gridrelated ICT The Chinese government promotes innovations surrounding smart grids mainly by focusing on the supply of smart grid technologies: on the one hand, the Chinese government counts on public enterprises as main drivers of smart grid innovations. On the other hand, it allocates significant financial funds to promote R\&D activities or to build up demonstration sites [50]. Specifically, in 2012 the MOST released a special plan for smart grids focusing on $\mathrm{R} \& \mathrm{D}$ and considering the $12^{\text {th }}$ five-year period (from 2011 to 2015). The smart grid special plan focuses on three main strategic goals:

- It is forward-looking and sets the agenda for the Chinese smart grid development after 2015. It promotes the development of so-called cutting-edge smart grid technologies which might be deployed after 2015 .

- It aims at ensuring that existing modern technologies such as those listed in appendix B are introduced very fast into the Chinese energy system.

- It highlights that China must keep up with world-class smart grid research developments and should carry out cutting-edge smart grid technology research.
The general idea behind the smart grid special plan is that the development of smart grids should be business-orientated and primarily rely on the innovation capacity of domestic companies, which are intended to achieve international technical dominance by 2020 . This will require a more profound and more effective involvement in international research cooperation and standardization processes.

The promotion of smart grid standards is another important channel for the government to influence the evolution of Chinese smart grids. One example for such activities is the work of the State Council, which has issued a plan for modifying and promoting the power equipment manufacturing industry [50]. Another example is the China Electric Power Research Institute directly emitting standards on Low Voltage Power Line Carrier Communication or Intelligent Control Network Data Terminal [50].

Policies focusing on the demand for smart grid technologies are of rather low importance for the Chinese government in its efforts to promote smart grids [50]. Note that this prevalence of supply-side policies together with the rather low importance of demand-side policies in China are a sign that, much like the situation in other countries, China's smart grid industry is still in the initial phase of its development [50].

The role of the ICT industry in promoting smart grids China's ICT sector is representative of the massive changes in China's industry and economy. Since the economic reforms in 1978, it has been growing rapidly with large inward and outward foreign direct investment flows and export-led activities [51]. Today, most of China's ICT companies are private companies that are not owned by the state. Many of them have been founded by foreign investors or companies. The Chinese strategy of building national champions has already yielded the creation of several ambitious companies which became global players [51]: Huawei Technologies, Lenovo, and ZTE are good examples of such companies. Huawei and ZTE are major players in the Global System for Mobile Communications (GSM), Code Division Multiple Access (CDMA), Optical and Digital Subscriber Line Access Multiplexer (DSLAM) equipment markets. Huawei Technologies in particular has emerged as a leading provider of tele- 
communications networks that increasingly challenges established competitors like Siemens, Cisco, and Alcatel [51].

Irrespective of the increasing importance of China's ICT sector, most ICT companies have few stakes in the strategic development of China's smart grid vision. Even though these companies act as component and technology suppliers, they are less engaged in the strategic development process, which is mainly pushed forward by the government, the grid companies, and the power generation companies. ${ }^{9}$

Regulatory challenges in the area of the role of information and communication

- There is a need for cutting-edge smart grid technology research to keep up with international level smart grid research developments.

- China's ICT industry consists of many ambitious and competitive companies, some of them global players. However, ICT industry is currently underrepresented in the strategic development of smart grids in China. Therefore, the large innovation potential of the ICT sector risks not being fully integrated in the Chinese smart grid development.

\section{Key findings}

- In the past 15 years, a series of reforms have greatly improved the efficiency, reliability, and environmental performance of the Chinese power sector. However, significant challenges remain: rapidly rising electricity demand, concerns about power system reliability and energy security, low average utilization rates of the grid infrastructure, environmental degradation and climate change.

- A core motivation for smart grids in China is their suspected positive impact on supply security and operational efficiency, especially on the distribution grid level. Peak shaving enabled by means of smart grid technologies plays an important role to increase supply security and operational efficiency. Smart grid technologies are also seen as a means to reduce RES integration costs, which is of critical importance given the Chinese government's aggressive RES expansion targets.

- Due to the absence of a common smart grid view in China and the contrary strategies on smart grid development among China's grid operators, there is still no unanimously accepted technological and organizational concept of smart grids in China. As a result, the uncertainty of potential smart grid investors regarding the future technological development is high.

- Some regulatory aspects of China's electric power system represent barriers for the effective and efficient development of smart grids in China:

- The absence of government guidelines for the long-term development of the electric power sector, overlapping responsibilities and conflicts of interests between different government authorities, and the lack of independence and law enforcement of the regulatory authority point to insufficient government leadership with regard to smart grid development.

- The market structure is dominated by China's grid operators, who are responsible for transmission, distribution, and retail. Innovative and new market actors, and specifically the ICT industry, are hardly involved in the smart grid development process.

- On-grid prices, retail prices, and the operating hours of power plants are fixed by government authorities. Grid operators' income depends on the difference between retail and on-grid prices - network charges are not explicitly calculated. Such a market design sets only few incentives for operational efficiency and does not incentivize investments in an efficient way.

- Grid expansion planning is organized in a topdown process with low transparency and little involvement of players other than government authorities and grid operators.

9 They seem to show even less engagement in China's smart grid development than international players such as Cisco or IBM.

Open Access This chapter is distributed under the terms of the Creative Commons Attribution Noncommercial License, which permits any noncommercial use, distribution, and reproduction in any medium, provided the original author(s) and source are credited. 


\section{References}

1 The Regulatory Assistance Project, “Recommendations for Power Sector Policy in China," The Regulatory Assistance Project, Beijing , 2013.

2 X. Qiu and H. Li, "Energy Regulation and Legislation in China," Environmental Law Reporter, vol. 7, pp. 10678 10693, 2012.

3 C. C. $\mathrm{Ni}$, "Analysis of Applicable Liberalization Models in China's Electric Power Market," International Public Economy Studies, vol. 16, 2006.

4 Asian Legal Information Institute, "Laws of the People's Republic of China - Electric Power Law of the People's Republic of China," Asian Legal Information Institute, December 28, 1995. [Online]. Available: http://www.asianlii.org/cn/ legis/cen/laws/eplotproc429/. [Accessed August 1, 2013].

5 China Daily, "China Meets Target of Closing Outdated Coal-Fueled Power Stations," China Daily, July 2010. [Online]. Available: http://www.chinadaily.com.cn/bizchina/2010-07/26/content_11047808.htm. [Accessed March 3, 2014].

6 J. Ke, L. Price, S. Ohshita, D. Fridley, N. Khanna, N. Zhou and M. Levine, "China's Industrial Energy Consumption Trends and Impacts of the Top-1000 Enterprises Energy-Saving Program and the Ten Key Energy-Saving Projects," Lawrence Berkeley National Laboratory, Berkeley, 2012.

7 State Council Information Office of the People's Republic of China (SCIO), “China's Energy Policy 2012," SCIO, Beijing, 2012.

8 E. Martinot and J. Li, “China's Latest Leap: An Update on Renewable Policy," Renewable Energy World, vol. 13, no. 4, pp. 51-57, 2010.

9 China Electricity Council (CEC), "Planning and Statistics," CEC, 2013. [Online]. Available: http://www.cec.org.cn/guihuayutongji/tongjxinxi/. [Accessed March 3, 2014].

10 Lawrence Berkeley National Laboratory, China Energy Databook, 2013.

11 The World Bank, “CO2 Emissions (kt),"The World Bank, 2013. [Online]. Available: http://data.worldbank.org/indicator/ EN.ATM.CO2E.KT/countries/1W?display=default. [Accessed August 27, 2013].

12 F. Kahrl, J. Williams, D. Jianhua and H. Junfeng, "Challenges to China's Transition to a Low Carbon Electricity System," Energy Policy, vol. 39, pp. 4032-4041, 2011.

13 H. Qin, "Challenges and Suggestions for the Development of China's Wind Power Industry," China Renewable Energy, vol. 2, no. 2, pp. 45-49, 2013.

14 W. Wang, "China Renewables and Non-Fossil Energy Utilization," China National Renewable Energy Centre (CNREC), Beijing, 2013.

15 National Bureau of Statistics of the People's Republic of China, China Energy Statistical Yearbook, Beijing: China Statistics-Press, 2012.

16 The World Bank, "GDP per Unit of Energy Use (Constant 2005 PPP \$ per kg of Oil Equivalent)," The World Bank, [Online]. Available: http://data.worldbank.org/indicator/ EG.GDP.PUSE.KO.PP.KD/countries. [Accessed March 3, 2014].
17 M. Davidson, "Politics of Power in China: Institutional Bottlenecks to Reducing Wind Curtailment Through Improved Transmission," IAEE Energy Forum, vol. 4, pp. 40-42, 2013.

18 D. Song, R. L. Zhi and X. C. Ya, "Leading the Smart Grid Revolution with UHV," in Advances in Power and Electrical Engineering, Mojie Sun, Gangui Yan and Yingjie Zhang, 2012, pp. 1862-1865.

19 Y. Yu, "The Needs and Requirements to Transform Power Distribution Grids in China,"Tianjin University, Tianjin, 2013.

20 China Electricity Council (CEC), "National Electricity Industry Statistical Newsletter 2011," CEC, 2011. [Online]. Available: http://www.cec.org.cn/xinxifabu/2012-01-13/78769. html. [Accessed November 19, 2013].

$21 \mathrm{H}$. Sun and Y. Zhang, "Research on and Design of Intelligence Distribution Grid System," China Rural Water and Hydropower, no. 2, 2012.

22 The World Bank, "China - Power Sector Transformer Efficiency Program Project," 2012. [Online]. Available: http:// documents.worldbank.org/curated/en/2012/01/15641795/ china-power-sector-transformer-efficiency-programproject. [Accessed February 4, 2014].

23 G. Tong, "Status Quo of the Smart Grid Development in China and Its Driving Forces," National Energy Administration (NEA), Oldenburg, 2013.

24 McKinsey \& Company, "Evolution of the Smart Grid in China," 2010. [Online]. Available: http://www.mckinsey. com/ /media/McKinsey/dotcom/client_service/EPNG/ PDFs/McK\%20on\%20smart\%20grids/MoSG_China_ VF.ashx. [Accessed November 8, 2013].

25 F. Han, M. Yin, J. Li, Y. Zhang and Q. Sun, "Discussions on related Issues of Smart Grid Development in China," Power System Technology, vol. 33, no. 15, pp. 47-53, 2009.

26 Q. Lu and S. Mei, "Basic Research on Vital Scientific Problem with Collapse Prevention and Optimal Operation of Large Scale Power Systems," China Basic Science, vol. Z, no. 1, 1999.

27 Y. Yu, J. Yang and B. Chen, "The Smart Grids in China - A Review," Energies, vol. 5, pp. 1321-1338, 2012.

28 Navigant Consulting, Inc., "Executive Summary: Smart Grid in China," 2012. [Online]. Available: http://www.navigantresearch.com/research/smart-grid-in-china. [Accessed November 8, 2013].

29 GIZ Renewable Energy Programme, "Key Actors in Chinese Energy Policy," Deutsche Gesellschaft für Internationale Zusammenarbeit (GIZ) GmbH, Beijing, 2013.

30 F. Han, M. Yin, J. Li, Y. Zhang and Q. Sun, "Discussions on Related Issues of Smart Grid Development in China," Power System Technology, vol. 33, no. 15, pp. 47-53, 2009.

31 US Environmental Protection Agency (USEPA), “China's Energy Markets: Anhui, Chongqing, Henan, Inner Mongolia, and Guizhou Provinces," USEPA, Washington D.C., 2012.

32 Fortune Magazine, "Global 500 - Our Annual Ranking of the World's Largest Corporations," Cable News Network, 2012. [Online]. Available: http://money.cnn.com/magazines/fortune/global500/2012/snapshots/10840.html. [Accessed August 7, 2013].

33 State Electricity Regulatory Commission (SERC), "Electricity Supervision Annual Report," SERC, Beijing, 2012. 
34 D. Patton, "China's State Grid: Too Big to Work?," NHST Media Group, April 2013. [Online]. Available: http://www.rechargenews.com/magazine/article1321523.ece. [Accessed August 7, 2013].

35 L. Xu and J. Alleyne, "SGT Insights - State Grids Investment in 2013," SGT Research, March 2013. [Online]. Available: http://www.sgtresearch.com/insights/2013/0305/147. html. [Accessed November 12, 2013].

36 G. Brunekreeft, Regulation and Competition Policy in the Electricity Market: Economic Analysis and German Experience, Baden-Baden: Nomos Verlagsgesellschaft $\mathrm{mbH}$, 2003.

37 G. Knieps, Wettbewerbsökonomie, Heidelberg: Springer, 2005.

38 S. Stoft, Power System Economics, Piscataway: The Institute of Electrical and Electronics Engineers, 2002.

39 G. Shi, X. Zheng and F. Song, "Estimating Elasticity for Residential Electricity Demand in China," The Scientific World Journal, vol. 2012, no. Article ID 395629, pp. 1-6, 2012.

40 Ministry of Finance of the People's Republic of China (MOF), "Interim Regulations Regarding Administration of the Renewable Electricity Surcharge Fund," MOF, 2012. [Online]. Available: http://jjs.mof.gov.cn/zhengwuxinxi/ zhengcefagui/201203/t20120329_638930.html. [Accessed August 8, 2013].

41 N. Metzger, "The Regulation of Electricity Transmission Line Investment in China," Carl von Ossietzky Universität, Oldenburg, 2013.

42 State Grid Corporation of China (SGCC), Framework and Roadmap for Strong \& Smart Grid Standards, Beijing: SGCC, 2010.

43 US Environmental Protection Agency (USEPA), "Electric Generation Ownership, Market Concentration and Auction Size,"Technical Support Document (TSD) for the Transport Rule Docket ID No. EPA-HQ-OAR-2009-0491, Washington D.C., 2010.

44 F. Kahrl, J. H. Williams and J. Hu, "The Political Economy of Electricity Dispatch Reform in China," Energy Policy, 2012.

45 State Council of the People's Republic of China, "Pilot Measures for Energy Efficient Dispatch," 2007. [Online]. Available: http://www.gov.cn/zwgk/2007-08/07/content_708486.htm. [Accessed January 17, 2014].

46 G. Ciwei and L. Yang, "Evolution of China's Power Dispatch Principle and the New Energy Saving Power Dispatch Policy," Energy Policy, vol. 38, no. 11, pp. 7346-7357, 2010.

47 Y. Ding and H. Yang, "Promoting Energy-Saving and Environmentally Friendly Generation Dispatching Model in China: Phase Development and Case Studies," Energy Policy, vol. 57, no. 0, pp. 109-118, 2013.

48 Azure International , "Azure China Cleantech Update," Azure International , 2013.

49 J. St. John, “China Wants Time-of-Use Pricing by 2015, One Meter per Home by 2017," Greentech Media Inc., January 2014. [Online]. Available: http://www.greentechmedia. com/articles/read/china-wants-time-of-use-pricing-by2015-one-meter-per-home-by-2017. [Accessed March 6, 2014].
50 C.-C. Lin, C.-H. Yang and J. Z. Shyua, "A Comparison of Innovation Policy in the Smart Grid Industry Across the Pacific: China and the USA," Energy Policy, vol. 57, pp. 119-132, 2013.

51 J.-P. Simon, "The ICT Landscape in BRICS Countries - China," Digiworld Economic Journal, vol. 85, pp. 191-202, 2012.

52 greentechmedia.com, "How China Will Impact the GridScale Energy Storage Market," greentechmedia.com, July 2012. [Online]. Available: http://www.greentechmedia. com/articles/read/How-China-Will-Impact-the-Grid-ScaleEnergy-Storage-Market. [Accessed June 7, 2014]. 